\title{
Direct Nucleophilic Acylation of Nitroalkenes Promoted by a Fluoride Anion/Thiourea Combination
}

\author{
Anita E. Mattson, Andrea M. Zuhl, Troy E. Reynolds and Karl A. Scheidt* \\ Department of Chemistry, Northwestern University, 2145 Sheridan Road, Evanston, Illinois, \\ 60208
}

\section{Supplemental Section Table of Contents}

1. General methods

S1-S2

2. Procedure and characterization data for carbinols

S2-S3

3. General procedure and characterization for protected thiazolium carbinols $\quad$ S3-S4

4. General procedure and characterization data for nucleophilic acylation of nitroalkenes

5. Asymmetric nucleophilic acylation of nitroalkenes

S7-S8

6. Determination of stereochemistry including crystal structure

S8-S8

7. HPLC trace of racemic 6

S9

8. HPLC trace of enantioenriched $\mathbf{6}$

S10

9. HPLC trace of racemic $\mathbf{1 6}$

$\mathrm{S} 11$

10. HPLC trace of enantioenriched $\mathbf{1 6}$

$\mathrm{S} 12$

11. HPLC trace of $\mathbf{1 6}$ crystals

S13

9. Selected NMR Spectra

S14-S19

General Information. All reactions were carried out under a nitrogen atmosphere in flamedried glassware with magnetic stirring. THF, $\mathrm{Et}_{2} \mathrm{O}, \mathrm{CH}_{2} \mathrm{Cl}_{2}, \mathrm{DMF}$ and toluene were purified by passage through a bed of activated alumina. ${ }^{1} \mathrm{CHCl}_{3}$ was purified by passage through a pad of alumina prior to use. Reagents were purified prior to use unless otherwise stated following the

1. Pangborn, A. B.; Giardello, M. A.; Grubbs, R. H.; Rosen, R. K.; Timmers, F. J. Organometal. 1996, 15, 15181520. 
guidelines of Perrin and Armarego. ${ }^{2}$ Purification of reaction products was carried out by flash chromatography using EM Reagent silica gel 60 (230-400 mesh). Analytical thin layer chromatography was performed on EM Reagent $0.25 \mathrm{~mm}$ silica gel $60-\mathrm{F}$ plates. Visualization was accomplished with UV light and anisaldehyde, ceric ammonium nitrate stain, potassium permangenate, or phosphomolybic acid followed by heating. Melting points were obtained on a Thomas Hoover capillary melting point apparatus and are uncorrected. Infrared spectra were recorded on a Bio-Rad Win FT-IR Pro spectrometer. ${ }^{1} \mathrm{H}-\mathrm{NMR}$ spectra were recorded on a Varian Inova $500(500 \mathrm{MHz})$ or Mercury $400(400 \mathrm{MHz})$ spectrometer and are reported in ppm using solvent as an internal standard $\left(\mathrm{CDCl}_{3}\right.$ at $7.26 \mathrm{ppm}$ ). Data are reported as (ap = apparent, $\mathrm{s}$ $=$ singlet, $\mathrm{d}=$ doublet, $\mathrm{t}=$ triplet, $\mathrm{q}=$ quartet, $\mathrm{m}=$ multiplet, $\mathrm{b}=$ broad; coupling constant(s) in $\mathrm{Hz}$; integration. Proton-decoupled ${ }^{13} \mathrm{C}-\mathrm{NMR}$ spectra were recorded on a Varian Inova 500 (125 $\mathrm{MHz})$ or Mercury $400(100 \mathrm{MHz})$ spectrometer and are reported in ppm using solvent as an internal standard $\left(\mathrm{CDCl}_{3}\right.$ at $\left.77.0 \mathrm{ppm}\right)$. Laser desorption mass spectra were obtained with $\mathrm{PE}$ BioSystems time-of-flight MALDI mass spectrometer with 2,5-dihydroxybenzoic acid as matrix. Electrospray ionization mass spectra were obtained on a Thermo Finnigan lcms ion trap mass spectrometer.

Tetrabutylammonium triphenyldifluorosilicate (TBAT) and tetramethylammonium fluoride (TMAF) were purchased from Aldrich and used without further purification. Nitroalkenes (2) were prepared according to the procedure of Feringa et al. ${ }^{3}$ 1-Nitrocyclohexene was purchased from Aldrich and used with further purification. Thiocarbanilide was used as received from Aldrich. Thiourea $\mathbf{1 7}$ was prepared according to the procedure of Soos and coworkers. ${ }^{4}$

\section{General Procedure for the Preparation of Protected Thiazolium Carbinols:}
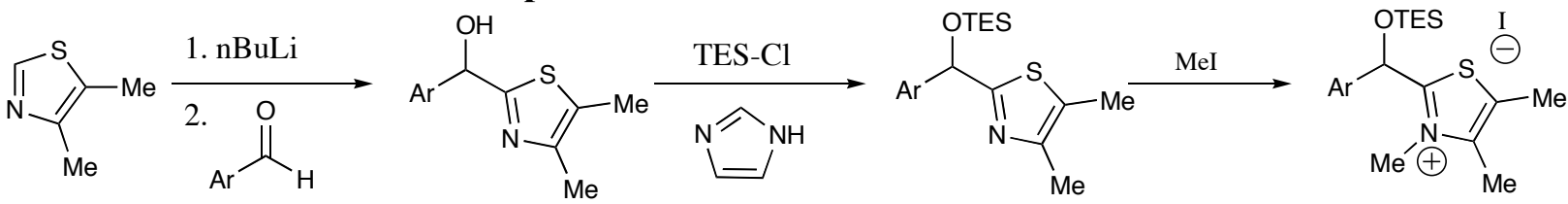

Synthesis of Carbinols:

A flame-dried round bottom flask under $\mathrm{N}_{2}$ was charged with 4,5-dimethylthiazole (1 mL, 9.45 mmol). THF $(45 \mathrm{~mL})$ was added and the solution was cooled to $78^{\circ} \mathrm{C}$. $n$-Butyl lithium $(1.9 \mathrm{M}, 6$ $\mathrm{mL}, 11.3 \mathrm{mmol}$ ) was added dropwise to the cold reaction mixture. The resulting dark red solution was stirred for $45 \mathrm{~min}$ at $78^{\circ} \mathrm{C}$. The aldehyde $(28.4 \mathrm{mmol})$ was then added, causing the solution to turn yellow, and the reaction was stirred for $1 \mathrm{~h}$ at $78^{\circ} \mathrm{C}$. The reaction was warmed to room temperature and stirred for $2 \mathrm{~h}$. At this time, water $(50 \mathrm{~mL})$ was added to quench the reaction. The reaction mixture was diluted with ethyl acetate $(200 \mathrm{~mL})$ and washed with water $(200 \mathrm{~mL})$. The aqueous layer was extracted two additional times with ethyl acetate $(100 \mathrm{~mL})$. The combined organic extracts were dried over sodium sulfate, filtered and concentrated in vacuo. The resulting residue was purified by recrystallization (ethyl acetate/hexanes).

\section{Partial Characterization of Carbinols:}

2. Perrin, D. D. and Armarego, W. L. Purification of Laboratory Chemicals; 3rd Ed., Pergamon Press, Oxford. 1988.

3. Duursma, A.; Minnaard, A.J.; Feringa, B.L. Tetrahedron 2002, 58, 5773-5778.

4 Vakulya, B.; Varga, S.; Csampai, A.; Soos, T. Org Lett 2005, 7, 1967-1969. 
<smiles>Cc1nc(C(O)c2ccc(Cl)cc2)sc1[N+](=O)[O-]</smiles>

(4-Chlorophenyl)(4,5-dimethylthiazol-2yl)methanol: Purified by recrystallization (ethyl acetate/hexanes), yielding $79 \%$ as a yellow solid. ${ }^{1} \mathrm{H}$ NMR (500 MHz, $\left.\mathrm{CDCl}_{3}\right) \delta 7.42$ (m, 2H); 7.35 (m, 2H); 5.93 $(\mathrm{s}, 3 \mathrm{H}) ; 4.46(\mathrm{~s}, 1 \mathrm{H}) ; 2.30(\mathrm{~s}, 3 \mathrm{H}) ; 2.28(\mathrm{~s}, 3 \mathrm{H})$.<smiles>Cc1nc(C(O)c2ccccc2)sc1C</smiles>

(4,5-Dimethylthiazol-2-yl)(phenyl)methanol: Purified by recrystallization (ethyl acetate/hexanes), yielding $1.94 \mathrm{~g}(84 \%)$ as a white solid. ${ }^{1} \mathrm{H}$ NMR $\left(500 \mathrm{MHz}, \mathrm{CDCl}_{3}\right) \delta 7.46(\mathrm{~m}, 2 \mathrm{H}) ; 7.38(\mathrm{~m}, 3 \mathrm{H}) ; 5.95(\mathrm{~s}$, $3 \mathrm{H}) ; 2.30(\mathrm{~s}, 3 \mathrm{H}) ; 2.29(\mathrm{~s}, 3 \mathrm{H})$.<smiles>Cc1nc(C(O)c2ccc3ccccc3c2)sc1C</smiles>

(4,5-Dimethylthiazol-2-yl)(naphthalen-3-yl)methanol: Purified by recrystallization (ethyl acetate/hexanes), yielding $1.99 \mathrm{~g}(78 \%)$ as an off white solid. ${ }^{1} \mathrm{H}$ NMR $\left(500 \mathrm{MHz}, \mathrm{CDCl}_{3}\right) \delta 7.98(\mathrm{~m}, 1 \mathrm{H}) ; 7.87$ $(\mathrm{m}, 1 \mathrm{H}) ; 7.86(\mathrm{~m}, 1 \mathrm{H}) ; 7.86(\mathrm{~m}, 1 \mathrm{H}) ; 7.59(\mathrm{~m}, 1 \mathrm{H}) ; 7.57(\mathrm{~m}, 1 \mathrm{H})$; $7.51(\mathrm{~m}, 1 \mathrm{H}) ; 6.14(\mathrm{~s}, 1 \mathrm{H}) ; 2.32(\mathrm{~s}, 3 \mathrm{H}) ; 2.30(\mathrm{~s}, 3 \mathrm{H})$.<smiles>COc1cccc(C(O)c2nc([N+](=O)[O-])c(C)s2)c1</smiles>

(3-Methoxyphenyl)(4,5-dimethylthiazol-2 -1$)$ methanol: Purified by recrystallization (ethyl acetate/hexanes), yielding $2.18 \mathrm{~g}(93 \%)$ as a yellow solid. ${ }^{1} \mathrm{H}$ NMR $\left(500 \mathrm{MHz}, \mathrm{CDCl}_{3}\right) \delta 7.30(\mathrm{~m}, 1 \mathrm{H}) ; 7.06(\mathrm{~m}, 2 \mathrm{H})$; $6.88(\mathrm{~m}, 1 \mathrm{H}) ; 5.93(\mathrm{~s}, 1 \mathrm{H}) ; 3.82(\mathrm{~s}, 3 \mathrm{H}) ; 2.30(\mathrm{~s}, 3 \mathrm{H}) ; 2.28(\mathrm{~s}, 3 \mathrm{H})$.<smiles>Cc1nc(C(O)c2ccc(Br)cc2)sc1[N+](=O)[O-]</smiles>

(4-Bromophenyl)(4,5-dimethylthiazol-2yl)methanol: Purified by recrystallization (ethyl acetate/hexanes), yielding $1.87 \mathrm{~g}(70 \%)$ as a yellow solid. ${ }^{1} \mathrm{H}$ NMR (500 MHz, $\left.\mathrm{CDCl}_{3}\right) \delta$ 7.51-7.50 (m, 2H); 7.377.35 (m, 2H); $5.90(\mathrm{~s}, 3 \mathrm{H}) ; 2.31(\mathrm{~s}, 3 \mathrm{H}) ; 2.30(\mathrm{~s}, 3 \mathrm{H})$.

\section{Typical Protection and Alkylation of Carbinols:}

To a flame-dried round bottom flask under $\mathrm{N}_{2}$ was added the carbinol $(7.3 \mathrm{mmol})$ followed by dichloromethane $(75 \mathrm{~mL})$. Next, triethylsilylchloride $(22 \mathrm{mmol})$ was added followed by imidazole $(8.0 \mathrm{mmol})$. The resulting suspension was then stirred overnight at room temperature. The reaction mixture was diluted with dichloromethane $(100 \mathrm{~mL})$ and washed three times with brine $(200 \mathrm{~mL})$. The combined aqueous layers were washed with dichloromethane. The combined organic layers were dried over $\mathrm{Na}_{2} \mathrm{SO}_{4}$, filtered and concentrated in vacuo. The pale yellow oil was used in the next step without further purification.

To the protected carbinol in a flame-dried round bottom flask was added iodomethane (10 eq) and the reaction was heated at reflux at $80{ }^{\circ} \mathrm{C}$. After $12 \mathrm{~h}$ the reaction was cooled to room temperature and concentrated in vacuo. Diethyl ether was then added to the yellow residue and the product precipitated. The solid was collected by vacuum filtration, washed with diethyl ether and dried under vacuum. The resulting product was used with further purification. 
<smiles></smiles>

1a was isolated as a pale yellow solid in a $50 \%$ yield over the two steps. $\mathrm{R}_{f}=0.49$ (20\% methanol/chloroform); Mp: $152-154^{\circ} \mathrm{C}$; IR (film) 1951, 2876, 1600, 1242, 2083, 1101, 806, $735 \mathrm{~cm}^{-1} ;{ }^{1} \mathrm{H}$ NMR $(500 \mathrm{MHz}$, $\left.\mathrm{CDCl}_{3}\right) \delta 7.62(\mathrm{~m}, 2 \mathrm{H}) ; 7.42(\mathrm{~m}, 2 \mathrm{H}) ; 7.05(\mathrm{~s}, 1 \mathrm{H}) ; 4.01(\mathrm{~s}, 3 \mathrm{H}) ; 2.52$ $(\mathrm{s}, 3 \mathrm{H}) ; 2.44(\mathrm{~s}, 3 \mathrm{H}) ; 0.89(\mathrm{t}, J=8.0 \mathrm{~Hz}, 9 \mathrm{H}) ; 0.69(\mathrm{~m}, 6 \mathrm{H}) ;{ }^{13} \mathrm{C} \mathrm{NMR}$ $\left(500 \mathrm{MHz}, \mathrm{CDCl}_{3}\right) \quad \delta 177.0,144.0,136.4,135.8,130.7,130.0,72.4$, 40.9, 13.3, 12.9, 7.0, 5.1; LRMS (MALDI-TOF): Mass calculated for $\mathrm{C}_{19} \mathrm{H}_{29} \mathrm{NO}_{2} \mathrm{SSi}[\mathrm{M}-\mathrm{I}]^{+}$, 382.14. Found 382.75.

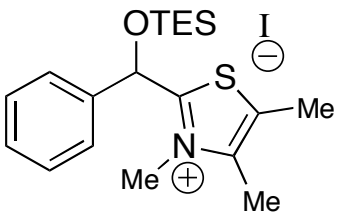

1b was isolated as a pale yellow solid in a $75 \%$ yield over the two steps. $\mathrm{R}_{f}=0.50$ (20\% methanol/chloroform); Mp: 150-151 ${ }^{\circ} \mathrm{C}$; IR (film) 2953, $2875,1604,1455,1073,1008,808,735 \mathrm{~cm}^{-1} ;{ }^{1} \mathrm{H}$ NMR $(500 \mathrm{MHz}$, $\left.\mathrm{CDCl}_{3}\right) \delta 7.56(\mathrm{~m}, 2 \mathrm{H}) ; 7.44(\mathrm{~m}, 3 \mathrm{H}) ; 6.86(\mathrm{~s}, 1 \mathrm{H}) ; 3.95(\mathrm{~s}, 3 \mathrm{H}) ; 2.51(\mathrm{~s}$, $3 \mathrm{H}) ; 2.43(\mathrm{~s}, 3 \mathrm{H}) ; 0.87(\mathrm{t}, J=7.6 \mathrm{~Hz}, 9 \mathrm{H}) ; 0.65(\mathrm{~m}, 6 \mathrm{H}) ;{ }^{13} \mathrm{C}$ NMR $(500$ $\left.\mathrm{MHz}, \mathrm{CDCl}_{3}\right) \delta 177.0,143.9,137.0,130.6,129.7,128.5,73.4,40.6,13.5,13.1,6.9,5.1$; LRMS (MALDI-TOF): Mass calculated for $\mathrm{C}_{19} \mathrm{H}_{30} \mathrm{NO}_{2} \mathrm{SSi}[\mathrm{M}-\mathrm{I}]^{+}, 348.60$. Found 348.80.

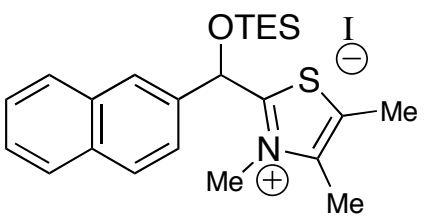

1c was isolated as a yellow solid in a $66 \%$ yield over the two steps. $\mathrm{R}_{f}=0.55$ (20\% methanol/chloroform); Mp: 160-161 ${ }^{\circ} \mathrm{C}$; IR (film) 2951, 2874, 1600, 1456, 1085, 1009, 807, $745 \mathrm{~cm}^{-1} ;{ }^{1} \mathrm{H}$ NMR $(500$ $\left.\mathrm{MHz}, \mathrm{CDCl}_{3}\right) \delta 8.21(\mathrm{~s}, 1 \mathrm{H}) ; 7.96(\mathrm{~m}, 1 \mathrm{H}) ; 7.90(\mathrm{~m}, 1 \mathrm{H}) ; 7.87(\mathrm{~m}$, $1 \mathrm{H}) ; 7.59(\mathrm{~m}, 1 \mathrm{H}) ; 7.57(\mathrm{~m}, 1 \mathrm{H}) ; 7.52(\mathrm{~m}, 1 \mathrm{H}) ; 3.97(\mathrm{~s}, 3 \mathrm{H}) ; 2.53(\mathrm{~s}$, $3 \mathrm{H}) ; 2.42(\mathrm{~s}, 3 \mathrm{H}) ; 0.87(\mathrm{t}, J=8.0 \mathrm{~Hz}, 9 \mathrm{H}) ; 0.68(\mathrm{~m}, 6 \mathrm{H}) ;{ }^{13} \mathrm{C} \mathrm{NMR}\left(500 \mathrm{MHz}, \mathrm{CDCl}_{3}\right) \delta 177.0$, 144.0, 134.1,133.9, 133.2, 130.7, 130.0, 128.7, 128.6, 128.1, 127.7, 127.3, 124.6, 73.6, 40.7, 13.4, 13.1, 6.9, 5.1; LRMS (MALDI-TOF): Mass calculated for $\mathrm{C}_{23} \mathrm{H}_{32} \mathrm{NOSSi}[\mathrm{M}-\mathrm{I}]^{+}, 398.20$. Found 398.70.

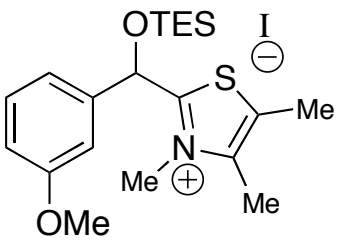

1d was isolated as a yellow solid in a $57 \%$ yield over the two steps. $\mathrm{R}_{f}=$ 0.55 (20\% methanol/chloroform); Mp: 118-120 ${ }^{\circ} \mathrm{C}$; IR (film) 2951, 2875, 1597, 1456, 1261, 1078, 1008, 806, $745 \mathrm{~cm}^{-1} ;{ }^{1} \mathrm{H}$ NMR $(500 \mathrm{MHz}$, $\left.\mathrm{CDCl}_{3}\right) \delta 7.34(\mathrm{~m}, \mathrm{IH}) ; 7.12(\mathrm{~s}, 1 \mathrm{H}) ; 7.10(\mathrm{~s}, \mathrm{IH}) ; 6.94(\mathrm{~m}, \mathrm{IH}) ; 6.79(\mathrm{~s}$, $\mathrm{IH}) ; 3.95(\mathrm{~s}, 3 \mathrm{H}) ; 3.84(\mathrm{~s}, 3 \mathrm{H}) ; 2.45(\mathrm{~s}, 3 \mathrm{H}) ; 2.43(\mathrm{~s}, 3 \mathrm{H}) ; 0.87(\mathrm{t}, J=8.0$ $\mathrm{Hz}, 9 \mathrm{H}) ; 0.65(\mathrm{~m}, 6 \mathrm{H}) \mathrm{ppm} ;{ }^{13} \mathrm{C}$ NMR $\left(500 \mathrm{MHz}, \mathrm{CDCl}_{3}\right) \quad \delta 177.2,160.4,143.9,138.5,130.8$, 130.5, 120.6, 115.9, 114.0, 73.3, 56.0, 40.7, 13.4, 12.9, 6.9, 5.1; LRMS (MALDI-TOF): Mass calculated for $\mathrm{C}_{20} \mathrm{H}_{34} \mathrm{NOSSi}[\mathrm{M}-\mathrm{I}]^{+}, 378.19$. Found 378.9.<smiles></smiles>

1e was isolated as a yellow solid in a $44 \%$ yield over the two steps. $\mathrm{R}_{f}$ $=0.55$ (20\% methanol/chloroform); Mp: $170-172{ }^{\circ} \mathrm{C}$; IR (film) 2955, 2876, 1597, 1486, 1242, 1080, 1010, 806, $731 \mathrm{~cm}^{-1} ;{ }^{1} \mathrm{H}$ NMR $(500$ $\left.\mathrm{MHz}_{\mathrm{CDCl}}\right) \delta$ 7.56(m, 4H); $7.04(\mathrm{~s}, \mathrm{IH}) ; 4.00(\mathrm{~s}, 3 \mathrm{H}) ; 2.52(\mathrm{~s}, 3 \mathrm{H})$; $2.44(\mathrm{~s}, 3 \mathrm{H}) ; 0.87(\mathrm{t}, J=7.9 \mathrm{~Hz}, 9 \mathrm{H}) ; 0.65(\mathrm{~m}, 6 \mathrm{H}) \mathrm{ppm} ;{ }^{13} \mathrm{C} \mathrm{NMR}$ $\left(500 \mathrm{MHz}, \mathrm{CDCl}_{3}\right) \delta 176.2,144.1,136.2,132.9,130.8,130.2,124.6,72.5,40.8,13.4,13.0,7.0$, 5.1; LRMS (MALDI-TOF): Mass calculated for $\mathrm{C}_{20} \mathrm{H}_{34} \mathrm{NOSSi}[\mathrm{M}-\mathrm{I}]^{+}, 424.4$. Found 426.9 .

\section{Typical Procedure for the Nucleophilic Acylation of Nitroalkenes:}


A dry screw-capped tube containing a magnetic stir bar was charged with thiourea 7 (76 mg, $0.335 \mathrm{mmol}$ ) in a nitrogen-filled glove box. Also in the box the protected thiazolium carbinol (260 mg, $0.510 \mathrm{mmol}$ ) and tetramethylammonium fluoride (TMAF, $48 \mathrm{mg}, 0.510 \mathrm{mmol}$ ) were weighed into two separate dram vials. All items were removed from box and the tube was put under a positive $\mathrm{N}_{2}$ pressure. Nitroalkene $(52 \mathrm{mg}, 0.335 \mathrm{mmol}$ ) was added to the thiourea in dicholoromethane $(1.6 \mathrm{~mL})$. Reaction mixture was cooled to $-40{ }^{\circ} \mathrm{C}$. Next, carbinol was added in dicholormethane $(0.5 \mathrm{~mL})$ and the reaction was allowed to stir for $5 \mathrm{~min}$. Last, TMAF was added in dicholormethane $(0.5 \mathrm{~mL})$. Reaction was allowed to stir at $-40{ }^{\circ} \mathrm{C}$ for $2-24 \mathrm{~h}$ until complete by thin layer chromatography (20\% ether/hexanes). Upon completion reaction was quenched with water and diluted with dicholormethane then allowed to warm to room temperature. The ayers were separated and the aqueous layer was extracted two additional times with dichloromethane $(30 \mathrm{~mL})$. The combined organic extracts were dried over sodium sulfate, filtered and concentrated in vacuo. The resulting orange residue was purified by flash column chromatography on silica gel.

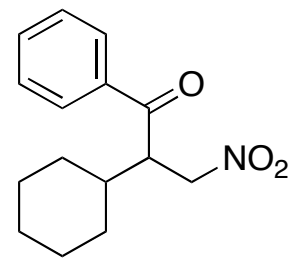

2-Cyclohexyl-3-nitro-1-phenylpropan-1-one (5): Purified with 5\% ether/hexanes, yielding $59 \mathrm{mg}(59 \%)$ of 5 as a colorless oil. $\mathrm{R}_{f}=0.39(20 \%$ ether/hexanes); IR (film) 2929, 2854, 1679, 1551, $1375 \mathrm{~cm}^{-1} ;{ }^{1} \mathrm{H}$ NMR (500 $\left.\mathrm{MHz}, \mathrm{CDCl}_{3}\right) \delta$ 8.00-7.98 (m, 2H); 7.63-7.60 (m, 1H); 7.52-7.49 (m, 2H); 5.09 (dd, $J=14.5,10.4 \mathrm{~Hz}, 1 \mathrm{H}) ; 4.53(\mathrm{dd}, J=14.6,3.3 \mathrm{~Hz}, 1 \mathrm{H}) ; 4.20-4.16$ (m, $1 \mathrm{H}) ; 1.72-1.62(\mathrm{~m}, 6 \mathrm{H}) ; 1.25-1.06(\mathrm{~m}, 4 \mathrm{H}) ; 0.96-0.91(\mathrm{~m}, 1 \mathrm{H}) ;{ }^{13} \mathrm{C} \mathrm{NMR}$ $\left(500 \mathrm{MHz}, \mathrm{CDCl}_{3}\right)$ б; 199.9, 136.8, 133.8, 129.1, 128.7, 73.9, 49.2, 39.5, 31.7, 29.8, 26.6, 26.4, 26.1; LRMS (ESI): Mass calculated for $\mathrm{C}_{15} \mathrm{H}_{19} \mathrm{NO}_{3}[\mathrm{M}]^{+}$, 261.32. Found $[\mathrm{M}+\mathrm{Na}]^{+}, 284.2$.

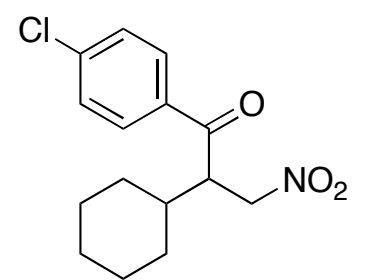

1-(4-Chlorophenyl)-2-cylcohexyl-3-nirtropropan-1-one (6): Purified with $5 \%$ ether/hexanes, yielding $78 \mathrm{mg}(78 \%)$ of 6 as a white solid. $\mathrm{R}_{f}=$ 0.39 (20\% ether/hexanes); Mp: $69.5-70.5{ }^{\circ} \mathrm{C}$; IR (film) 2929, 1680, 1554, $1375 \mathrm{~cm}^{-1} ;{ }^{1} \mathrm{H}$ NMR $\left(500 \mathrm{MHz}, \mathrm{CDCl}_{3}\right) \delta$ 7.94-7.92 (m, 2H); 7.49-7.47 $(\mathrm{m}, 2 \mathrm{H}) ; 5.07(\mathrm{dd}, J=14.7,10.4 \mathrm{~Hz}, 1 \mathrm{H}) ; 4.53(\mathrm{dd}, J=15.0,3.4 \mathrm{~Hz}, 1 \mathrm{H})$; 4.13-4.09 (m, 1H); 1.73-1.61 (m, 6H); 1.20-1.05 (m, 4H); 0.95-0.88 (m, $1 \mathrm{H}){ }^{13} \mathrm{C}$ NMR $\left(500 \mathrm{MHz}, \mathrm{CDCl}_{3}\right) \quad \delta 198.9,140.4,135.2,130.1,129.5,73.9,49.1,39.5,31.9$, 29.9, 26.6, 26.4, 26.0; LRMS (ESI): Mass calculated for $\mathrm{C}_{15} \mathrm{H}_{18} \mathrm{ClNO}_{3}[\mathrm{M}]^{+}, 295.8$. Found $[\mathrm{M}+\mathrm{Na}]^{+}, 319.1$.

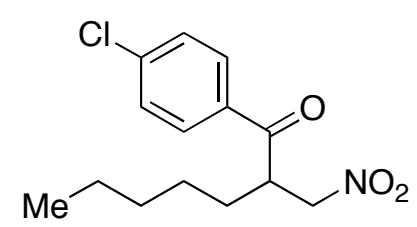

1-(4-Chlorophenyl)-2-(nitromethyl)heptan-1-one (9): Purified with $5 \%$ ether/hexanes, yielding $65 \mathrm{mg}(65 \%)$ of 9 as a colorless oil. $\mathrm{R}_{f}=$ 0.42 (20\% ether/hexanes); IR (film) 2931, 2862, 1683, 1555, $1378 \mathrm{~cm}^{-}$ ${ }^{1}$; ${ }^{1} \mathrm{H}$ NMR $\left(500 \mathrm{MHz}, \mathrm{CDCl}_{3}\right) \delta$ 7.94-7.92 (m, 2H); 7.50-7.48 (m, $2 \mathrm{H}) ; 5.01(\mathrm{dd}, J=14.6,9.5 \mathrm{~Hz}, 1 \mathrm{H}) ; 4.49(\mathrm{dd}, J=14.6,4.2 \mathrm{~Hz}, 1 \mathrm{H})$; 4.21-4.20 (m, 1H); 1.72-1.66 (m, 1H); 1.55-1.50 (m, 1H); 1.29-1.24 (m, 6H); 0.84-0.82 (m, $3 \mathrm{H}) ;{ }^{13} \mathrm{C} \mathrm{NMR}\left(500 \mathrm{MHz}, \mathrm{CDCl}_{3}\right) \quad \delta 198.9,140.6,134.4,130.2,129.6,75.2,44.0,31.8,30.3$, 26.6, 22.5, 14.1; LRMS (ESI): Mass calculated for $\mathrm{C}_{14} \mathrm{H}_{18} \mathrm{ClNO}_{3}[\mathrm{M}]^{+}, 283.8$. Found $\left[\mathrm{M}-\mathrm{NO}_{2}\right]^{+}$, 236.3 . 
<smiles>CC(C)C(C[N+](=O)[O-])C(=O)c1ccc(Cl)cc1</smiles>

1-(4-Chlorophenyl)-3-methyl-2-(nitromethyl)butan-1-one (10): Purified with $5 \%$ ether/hexanes, yielding $73 \mathrm{mg}(73 \%)$ of $\mathbf{1 0}$ as a colorless oil. $\mathrm{R}_{f}=$ 0.32 (20\% ether/hexanes); IR (film) 2967, 2932, 1681, 1550, $1375 \mathrm{~cm}^{-1} ;{ }^{1} \mathrm{H}$ NMR $\left(500 \mathrm{MHz}, \mathrm{CDCl}_{3}\right)$ ठ 7.94-7.93 (m, 2H); 7.50-7.48 (m, 2H); $5.09(\mathrm{dd}$, $J=10.5,4.0 \mathrm{~Hz}, 1 \mathrm{H}) ; 4.54(\mathrm{dd}, J=11,3.5 \mathrm{~Hz}, 1 \mathrm{H}) ; 4.14-4.11(\mathrm{~m}, 1 \mathrm{H})$; $2.14-2.11(\mathrm{~m}, 1 \mathrm{H}) ; 1.04(\mathrm{~d}, J=7.0 \mathrm{~Hz}, 3 \mathrm{H}) ; 0.88(\mathrm{~d}, J=7.0 \mathrm{~Hz}, 3 \mathrm{H})$;

${ }^{13} \mathrm{C}$ NMR $\left(500 \mathrm{MHz}, \mathrm{CDCl}_{3}\right) \delta 198.8,140.4,135.0,130.1,129.5,73.3,49.5,29.5,21.2,19.1$;<smiles>CC(O)C(C[N+](=O)[O-])C(=O)c1ccc(Cl)cc1</smiles>

3-(Benzyloxy)-1-(4-chlorophenyl)-2-(nitromethyl)butan-1-one (11): Purified using a gradient from $5 \%$ to $40 \%$ ether/hexanes, yielding $80 \mathrm{mg}$ $(80 \%)$ of 11 , a non-separable mixture of diastereomors, as a colorless oil. $\mathrm{R}_{f}=0.20$ (20\% ether/hexanes); IR (film) 2978, 2919, 2872, 1555, 1378 $\mathrm{cm}^{-1} ;{ }^{1} \mathrm{H}$ NMR $\left(500 \mathrm{MHz}, \mathrm{CDCl}_{3}\right) \delta$ 7.95-7.93 (m, 2H); 7.82-7.81 (m, $2 \mathrm{H})$; 7.50-7.48 (m, 2H); 7.44-7.42 (m, 2H); 7.39-7.31 (m, 6H); 7.29-7.27 $(\mathrm{m}, 2 \mathrm{H}) ; 7.24-7.23(\mathrm{~m}, 2 \mathrm{H}) ; 5.16(\mathrm{dd}, J=14.7,10.2 \mathrm{~Hz}, 1 \mathrm{H}) ; 5.70(\mathrm{dd}, J=15.0,9.7 \mathrm{~Hz}, 1 \mathrm{H})$; $4.80(\mathrm{dd}, J=15.0,3.5 \mathrm{~Hz}, 1 \mathrm{H}) ; 4.71(\mathrm{dd}, J=14.8,2.8 \mathrm{~Hz}, 1 \mathrm{H}) ; 4.66(\mathrm{~d}, J=12.1 \mathrm{~Hz}, 1 \mathrm{H}), 4.58(\mathrm{~d}$, $J=11.7 \mathrm{~Hz}, 1 \mathrm{H}) ; 4.54(\mathrm{~m}, 1 \mathrm{H}) ; 4.47(\mathrm{~d}, J=11.9 \mathrm{~Hz}, 1 \mathrm{H}) ; 4.37(\mathrm{~m}, 1 \mathrm{H}) ; 4.34(\mathrm{~d}, J=11.7 \mathrm{~Hz}$, $1 \mathrm{H}) ; 3.94(\mathrm{~m}, 1 \mathrm{H}) ; 3.82(\mathrm{~m}, 1 \mathrm{H}) ; 1.23(\mathrm{~d}, J=6.2 \mathrm{~Hz}, 3 \mathrm{H}) ; 1.13(\mathrm{~d}, J=6.2 \mathrm{~Hz}, 3 \mathrm{H}) ;{ }^{13} \mathrm{C} \mathrm{NMR}$ $\left(500 \mathrm{MHz}, \mathrm{CDCl}_{3}\right) \delta 197.5,196.7,140.6,140.6,137.6,137.4,135.0,134.5,130.3,130.2,129.5$, $129.4,128.9,128.8,128.4,128.3,128.1,128.0,73.7,73.6,72.8,71.6,71.4,71.1,50.3,49.6$, 18.2, 16.4; LRMS (ESI): Mass calculated for $\mathrm{C}_{18} \mathrm{H}_{18} \mathrm{ClNO}_{4}[\mathrm{M}]^{+}, 347.8$. Found $[\mathrm{M}+\mathrm{M}]^{+}, 696.2$.

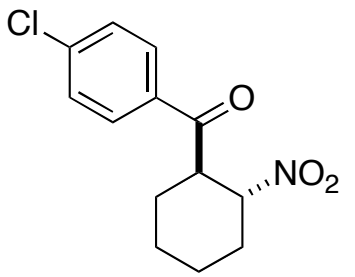

(4-Chlorophenyl)(2-nitrocyclohexyl)methanone (12): Purified with 5\% ether/hexanes, yielding $80 \mathrm{mg}(80 \%)$ of $\mathbf{1 2}$, the trans diastereomer, as a white solid. $\mathrm{R}_{f}=0.29$ (20\% ether/hexanes); Mp: $78-79{ }^{\circ} \mathrm{C}$; IR (film) 2943, 2864, 1680, 1546, $1379 \mathrm{~cm}^{-1} ;{ }^{1} \mathrm{H}$ NMR (500 MHz, $\left.\mathrm{CDCl}_{3}\right) \delta$ 7.95$7.93(\mathrm{~m}, 2 \mathrm{H}) ; 7.51-7.49(\mathrm{~m}, 2 \mathrm{H}) ; 4.98(\mathrm{ddd}, J=11.9,11.9,3.3 \mathrm{~Hz}, 1 \mathrm{H})$;

3.96 (ddd. $J=11.9,11.9,2.9 \mathrm{~Hz}, 1 \mathrm{H}) ; 2.65-2.63(\mathrm{~m}, 1 \mathrm{H}) ; 2.17-2.14$ (m, $1 \mathrm{H}) ; 2.04-2.02(\mathrm{~m}, 1 \mathrm{H}) ; 1.90-1.80(\mathrm{~m}, 2 \mathrm{H}) ; 1.55-1.33(\mathrm{~m}, 3 \mathrm{H}) ;{ }^{13} \mathrm{C} \mathrm{NMR}\left(500 \mathrm{MHz}, \mathrm{CDCl}_{3}\right) \delta$ 198.9, 140.4, 133.7, 130.1, 129.4, 95.0, 84.9, 48.0, 31.8, 29.4, 25.0, 24.9 LRMS (ESI): Mass calculated for $\mathrm{C}_{13} \mathrm{H}_{14} \mathrm{ClNO}_{3}[\mathrm{M}]^{+}$, 267.7. Found $[\mathrm{M}+\mathrm{M}+\mathrm{Na}]^{+}$, 557.0. Diastereomer ratio was determined by $500 \mathrm{MHz}{ }^{1} \mathrm{H}$ NMR.

\section{Determination of Conformation of $\beta$-Nitroketone 12:}

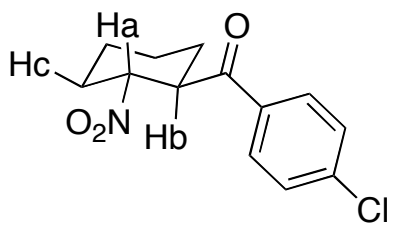

Proton decoupling experiments were preformed in order to determine the conformation of $\mathbf{1 2}$.

\begin{tabular}{cc} 
Decoupled Proton & $J$-Values \\
\hline $\mathrm{H}_{\mathrm{a}}$ & $J \mathrm{H}_{\mathrm{b}}=12.3,2.9 \mathrm{~Hz}$ \\
$\mathrm{H}_{\mathrm{b}}$ & $\mathrm{JH}_{\mathrm{a}}=11.9,3.3 \mathrm{~Hz}$ \\
$\mathrm{H}_{\mathrm{c}}$ & $J \mathrm{H}_{\mathrm{a}}=11.5,11.5 \mathrm{~Hz}$
\end{tabular}




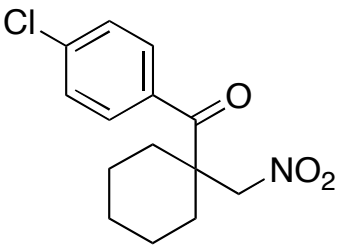

4-Chlorophenyl)(1-(nitromethyl)cyclohexyl)methanone (13): Purified with $5 \%$ ether/hexanes, yielding $56 \mathrm{mg}(56 \%)$ of 13 as a colorless oil. $\mathrm{R}_{f}=$ 0.29 (20\% ether/hexanes); IR (film) 2936, 2862, 1682, 1551, $13378 \mathrm{~cm}^{-1}$;

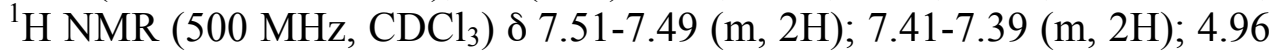
$(\mathrm{s}, 2 \mathrm{H}) ; 1.76-1.74(\mathrm{~m}, 2 \mathrm{H}) ; 1.60-1.58(\mathrm{~m}, 3 \mathrm{H}) ; 1.50-1.43(\mathrm{~m}, 2 \mathrm{H}) ; 1.36-$ $1.33(\mathrm{~m}, 1 \mathrm{H}) ;{ }^{13} \mathrm{C}$ NMR $\left(500 \mathrm{MHz}, \mathrm{CDCl}_{3}\right) \delta 206.3,137.5,126.9,128.8$,

79.6, 51.8, 32.1, 25.4, 22.0; LRMS (ESI): Mass calculated for $\mathrm{C}_{14} \mathrm{H}_{16} \mathrm{ClNO}_{2}[\mathrm{M}]^{+}, 281.7$. Found $\left[\mathrm{M}-\mathrm{NO}_{2}\right]^{+}, 236.4$.

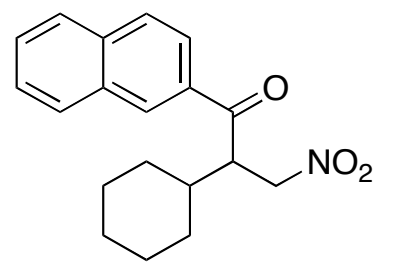

2-Cylcohexyl-1-(napthalen-3-yl)-3-nitropropane-1-one (14): Purified with $5 \%$ ether/hexanes, yielding $80 \mathrm{mg}(80 \%)$ of 14 as a colorless oil. $\mathrm{R}_{f}=0.28$ (20\% ether/hexanes); IR (film) 2928, 2854, 1674, 1551, 1375 $\mathrm{cm}^{-1} ;{ }^{1} \mathrm{H}$ NMR $\left(500 \mathrm{MHz}, \mathrm{CDCl}_{3}\right) \delta 8.52(\mathrm{~s}, 1 \mathrm{H}) ; 8.05-8.00(\mathrm{~m}, 2 \mathrm{H})$; 7.94-7.89 (m, 2H); 7.64-7.56 (m, 2H); $5.15(\mathrm{dd}, J=14.5,10.2 \mathrm{~Hz}, 1 \mathrm{H})$; $4.59(\mathrm{dd}, J=14.6,3.1 \mathrm{~Hz}, 1 \mathrm{H}) ; 4.35(\mathrm{~m}, 1 \mathrm{H}) ; 1.81-1.61(\mathrm{~m}, 6 \mathrm{H}) ; 1.21-$ $0.96(\mathrm{~m}, 5 \mathrm{H}) ;{ }^{13} \mathrm{C} \mathrm{NMR}\left(500 \mathrm{MHz}, \mathrm{CDCl}_{3}\right) \delta 200.0,136.0,134.3,132.8,130.5,130.0,129.1$, 129.0, 128.1, 127.2, 124.3, 74.1, 49.2, 39.7, 31.7, 30.0, 26.6, 26.5, 26.1; LRMS (ESI): Mass calculated for $\mathrm{C}_{19} \mathrm{H}_{21} \mathrm{NO}_{2}[\mathrm{M}]^{+}$, 311.4. Found $[\mathrm{M}+\mathrm{H}]^{+}, 312.4$.

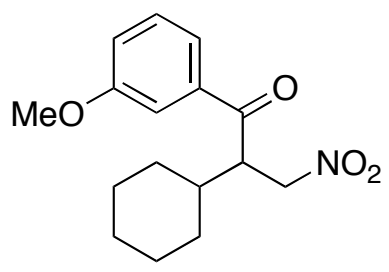

2-Cyclohexyl-1-(3-methoxyphenyl)-3-nitropropan-1-one (15): Purified with 5\%-40\% ether/hexanes, yielding $60 \mathrm{mg}(60 \%)$ of 15 as a colorless oil. $\mathrm{R}_{f}=0.38$ (20\% ether/hexanes); IR (film) 2930, 2854, 1680, 1554, $1266 \mathrm{~cm}^{-1} ;{ }^{1} \mathrm{H}$ NMR $\left(500 \mathrm{MHz}, \mathrm{CDCl}_{3}\right) \delta$ 7.59-7.58 (m, $1 \mathrm{H}) ; 7.52(\mathrm{~s}, 1 \mathrm{H}) ; 7.45-7.42(\mathrm{~m}, 1 \mathrm{H}) ; 7.18-7.16(\mathrm{~m}, 1 \mathrm{H}) ; 5.09(\mathrm{dd}, J$ $=14.5,10.4 \mathrm{~Hz}, 1 \mathrm{H}) ; 4.55(\mathrm{dd}, J=14.5,2.9 \mathrm{~Hz}, 1 \mathrm{H}) ; 4.2(\mathrm{~m}, 1 \mathrm{H}) ; 3.89$ $(\mathrm{s}, 3 \mathrm{H}) ; 1.73-1.63(\mathrm{~m}, 6 \mathrm{H}) ; 1.23-1.08(\mathrm{~m}, 4 \mathrm{H}) ; 0.98-0.93(\mathrm{~m}, 1 \mathrm{H})$; ${ }^{13} \mathrm{C} \mathrm{NMR}\left(500 \mathrm{MHz}, \mathrm{CDCl}_{3}\right) \delta 199.7,160.2,138.2,130.1,121.3,120.2,113.1,73.9,55.7,49.3$, 39.5, 31.7, 29.8, 26.6, 26.4, 26.1; LRMS (ESI): Mass calculated for $\mathrm{C}_{16} \mathrm{H}_{21} \mathrm{NO}_{4}[\mathrm{M}]^{+}, 291.3$. Found $[\mathrm{M}+\mathrm{Na}+\mathrm{H}]^{+}, 315.5$.

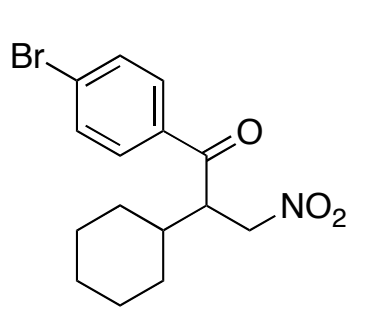

1-(4-Bromophenyl)-2-cyclohexyl-3-nitropropan-1-one (16): Purified with $2-6 \%$ ether/hexanes, yielding $81 \mathrm{mg}(81 \%)$ of $\mathbf{1 6}$ as a colorless oil. $\mathrm{R}_{f}=0.29$ (20\% ether/hexanes); $\mathrm{Mp}=95.5-97{ }^{\circ} \mathrm{C}$; IR (film) 2929, 2854, $1680,1554,1375,1250 \mathrm{~cm}^{-1} ;{ }^{1} \mathrm{H}$ NMR $\left(500 \mathrm{MHz}, \mathrm{CDCl}_{3}\right) \delta 7.87-7.86$ (m, 2H); 7.67-7.65 (m, 2H); $5.09(\mathrm{dd}, J=15.0,10.7 \mathrm{~Hz}, 1 \mathrm{H}) ; 4.55$ (dd, $J$ $=15.0,3.4 \mathrm{~Hz}, 1 \mathrm{H}) ; 4.13-4.10(\mathrm{~m}, 1 \mathrm{H}) ; 1.74-1.62(\mathrm{~m}, 6 \mathrm{H}) ; 1.26-1.06(\mathrm{~m}$, $4 \mathrm{H})$; 0.97-0.89 (m, 1H); $\left.{ }^{13} \mathrm{C} \mathrm{NMR} \mathrm{(500} \mathrm{MHz,} \mathrm{CDCl}_{3}\right) \quad \delta 199.1,135.6$, 132.4, 130.2, 129.1, 73.9, 55.7, 49.1, 39.5, 31.7, 29.9, 26.6, 26.4, 26.0; LRMS (ESI): Mass calculated for $\mathrm{C}_{18} \mathrm{H}_{18} \mathrm{BrNO}_{2}[\mathrm{M}]^{+}$, 340.2. Found $[\mathrm{M}+\mathrm{Na}]^{+}, 363.5$.

\section{Asymmetric Nucleophilic Acylation of Nitroalkenes:}

A dry screw-capped tube containing a magnetic stir bar was charged with thiourea 17 (200 mg, $0.335 \mathrm{mmol}$ ) in a nitrogen-filled glove box. Also in the box the protected thiazolium carbinol 1a (260 mg, $0.510 \mathrm{mmol}$ ) and tetramethylammonium fluoride (TMAF, $48 \mathrm{mg}, 0.510 \mathrm{mmol}$ ) were weighed into two separate dram vials. All items were removed from box and the tube was put 
under a positive $\mathrm{N}_{2}$ pressure. Nitroalkene $(52 \mathrm{mg}, 0.335 \mathrm{mmol}$ ) was added to the thiourea in dicholoromethane $(1.6 \mathrm{~mL})$. Reaction mixture was cooled to $-78^{\circ} \mathrm{C}$. Next, carbinol was added in dicholormethane $(0.5 \mathrm{~mL})$ and the reaction was allowed to stir for $5 \mathrm{~min}$. Last, TMAF was added in dicholormethane $(0.5 \mathrm{~mL})$. Reaction was allowed to stir at $-78{ }^{\circ} \mathrm{C}$ for $2-24 \mathrm{~h}$ until complete by thin layer chromatography ( $20 \%$ ether/hexanes). Upon completion reaction was quenched with water and diluted with dicholormethane then warmed to room temperature. The layers were separated and the aqueous layer was extracted two additional times with dichloromethane $(30 \mathrm{~mL})$. The combined organic extracts were dried over sodium sulfate, filtered and concentrated in vacuo. The resulting orange residue was purified by flash column chromatography on silica gel.

Enantiomeric excess determined by HPLC on a Chiralcel OD-H column. 10\% IPA/Hexanes, $1 \mathrm{~mL} / \mathrm{min}$.

\section{Determination of Stereochemistry:}

The absolute stereochemistry was determined by X-ray crystallography of $\mathbf{1 6}$. The asymmetric nucleophilic acylation was carried out using the 4-Br-Ph thiazolium carbinol (1e) and nitroalkene 2a to yield 16 with an enantiomeric excess of $70 \%$. Enantiomeric excess determined by HPLC on a Chiralcel OD-H column. $10 \% \mathrm{IPA} /$ Hexanes, $1 \mathrm{~mL} / \mathrm{min}$. Recrystallized from ether/hexanes.

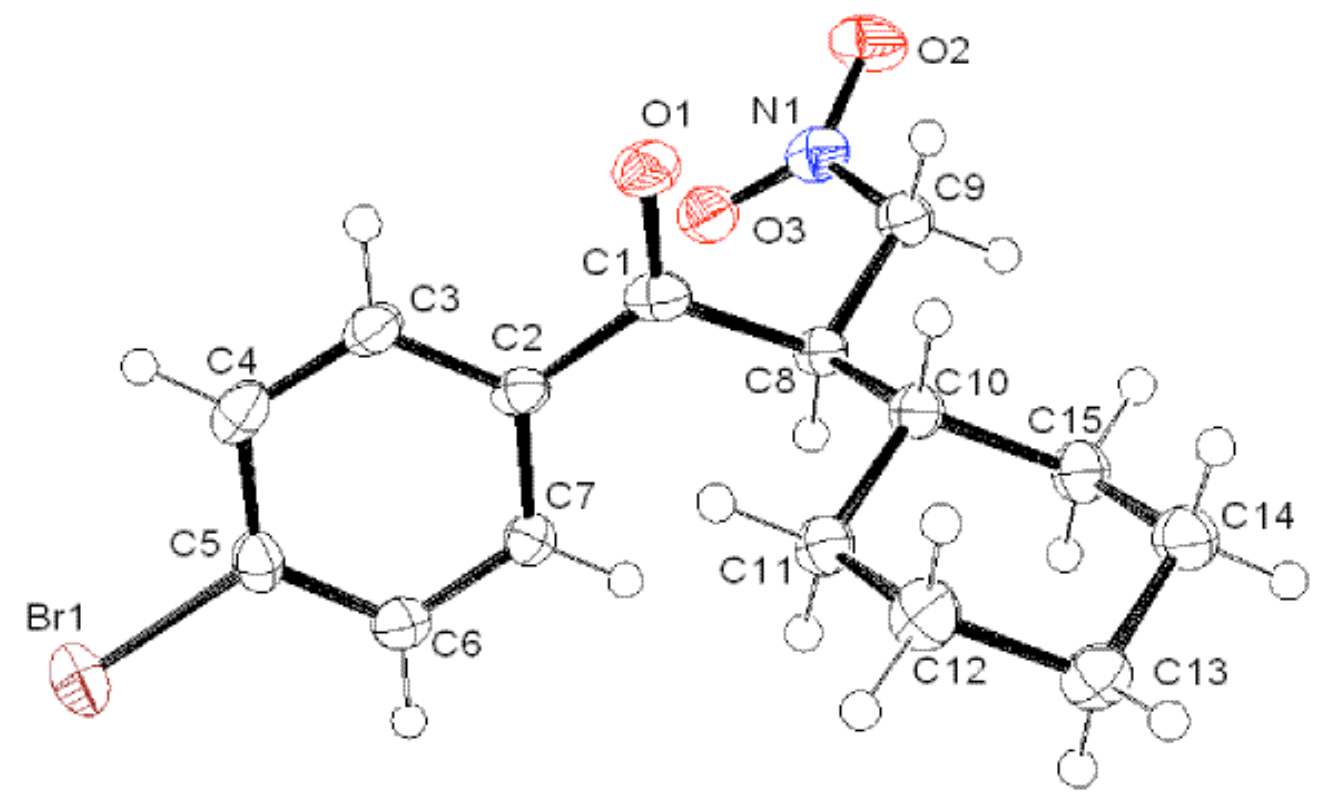




\section{HPLC trace of racemic 6:}

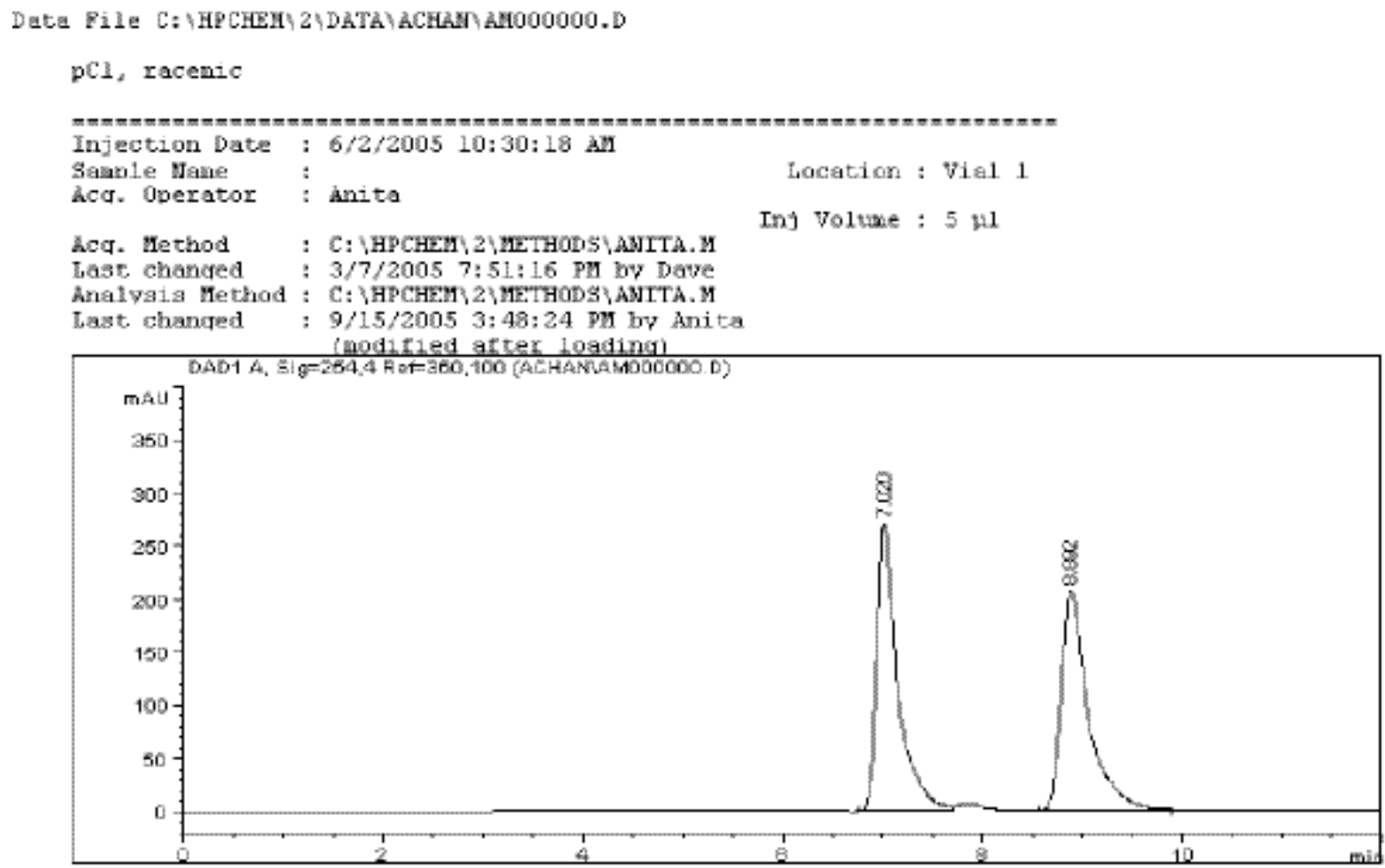

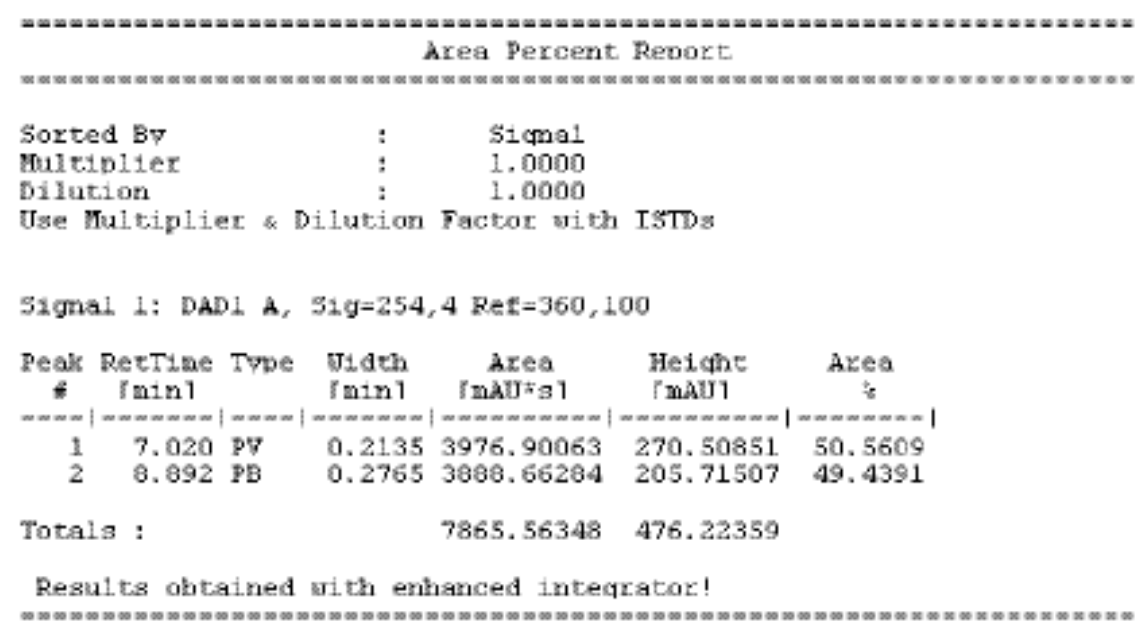

$* * *$ End of Report $* * *$ 


\section{HPLC trace of enantioenriched 6:}

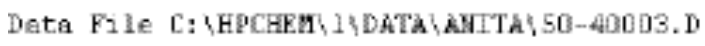

$-78$

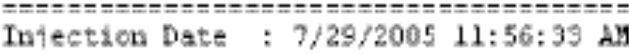

Sanole Nane : 50-4

Aco. Doerator : Ansta

ACq. Instrutere : Instndaene 1

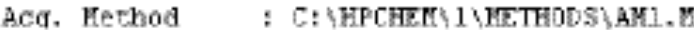

Last chenoed : 7/29/2005 11:55:55 AY by Anico

inodified after loading

Analvsis Hethod: C: \HPCHEI $1 \backslash$ IETHDDS〉, iK1.K

Last chanued : 9/15/2005 3:56:44 PM bv ànita

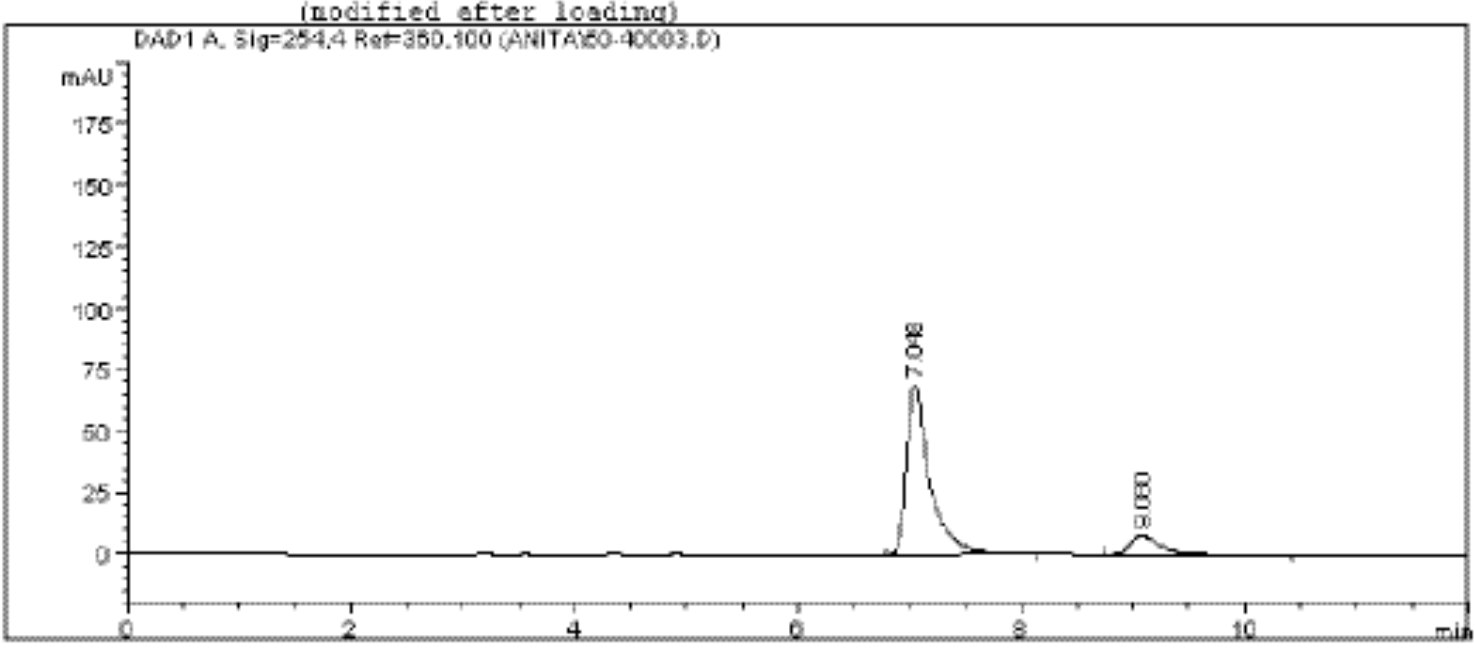

Location : Pial 3

Inj Polue : 5 fl

Thy voluae : 5 HI

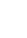




\section{HPLC trace of Racemic 16:}

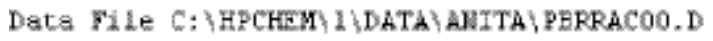

pBr racenic

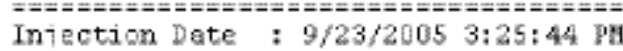

Acq. Inecrusent : Instrusent 1

Acd. Wethod : C: \HPCHEN $1 \backslash$ RETHODS $\backslash$ AX1.M

Inj volume : $10 \mu 1$

Lase chanded : 9/23/2005 3:25:08 PM bv Anica

(rodified after loading)

Analysis He thod: C: \HPCHEM $1 \backslash$ UETHODS MH.M

Last chenued : 9/23/2005 3:42:06 Pt bv Anits

(nodified after loading)

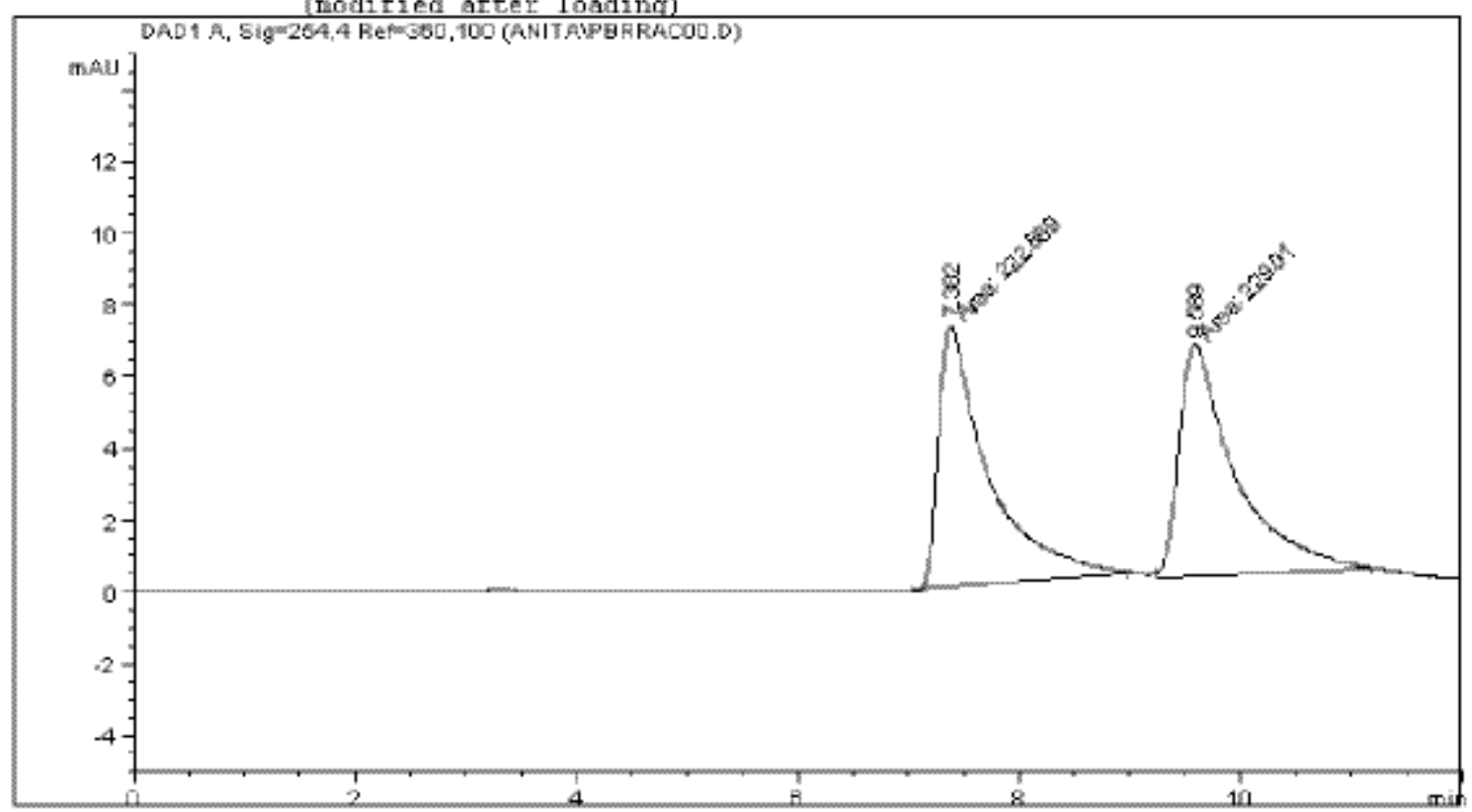

Area Percent Report

\begin{tabular}{|c|c|c|}
\hline Sorted By & : & Sicnal \\
\hline Multinlier & : & 1. 0000 \\
\hline Dilution & : & 1.0000 \\
\hline
\end{tabular}

Signal 1: DAD1 A, Sig-254,4 Ref $=360,100$

\begin{tabular}{|c|c|c|c|c|c|}
\hline $\begin{array}{c}\text { Feas } \\
\quad \#\end{array}$ & $\begin{array}{l}\text { RetTine Type } \\
\text { rinin }\end{array}$ & $\begin{array}{l}\text { vider } \\
\text { frin? }\end{array}$ & 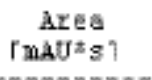 & $\begin{array}{l}\text { Heithe } \\
\text { 'xADU1 }\end{array}$ & $\begin{array}{c}\text { Area } \\
\text { : }\end{array}$ \\
\hline & $\begin{array}{l}3.382 \mathrm{kM} \\
0.589 \mathrm{kM}\end{array}$ & $\begin{array}{l}0.5138 \\
0.5917\end{array}$ & $\begin{array}{l}222.86940 \\
229.01047\end{array}$ & $\begin{array}{l}7.2289 \\
6.4507\end{array}$ & $\begin{array}{l}3205 \\
5795\end{array}$ \\
\hline
\end{tabular}

Totals : $\quad 451.87987 \quad 13.67976$

Results obtained with enhanced interrator! 


\section{HPLC trace of enantioenriched 16:}

Data File C: \HFCHEH\L\DATA \ANTTA 70-40000.D

pBr vith cquinine thiourea

Injection Date : 9/2/2005 1:56:56 PK

Sample Hane :

Aco. Overator : inita

Location : 71 al 31

Aca. Instrument : Instruent 1

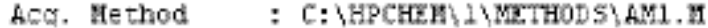

Inj Folune : $5 \mu 1$

Laat chanced : 9/2/2005 9:52:57 AH bv Anita

inodified after loadinci

Analysis Tethod : C: \HPCHEM,1YMETHODSYCHO S.X

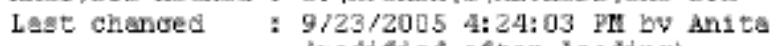

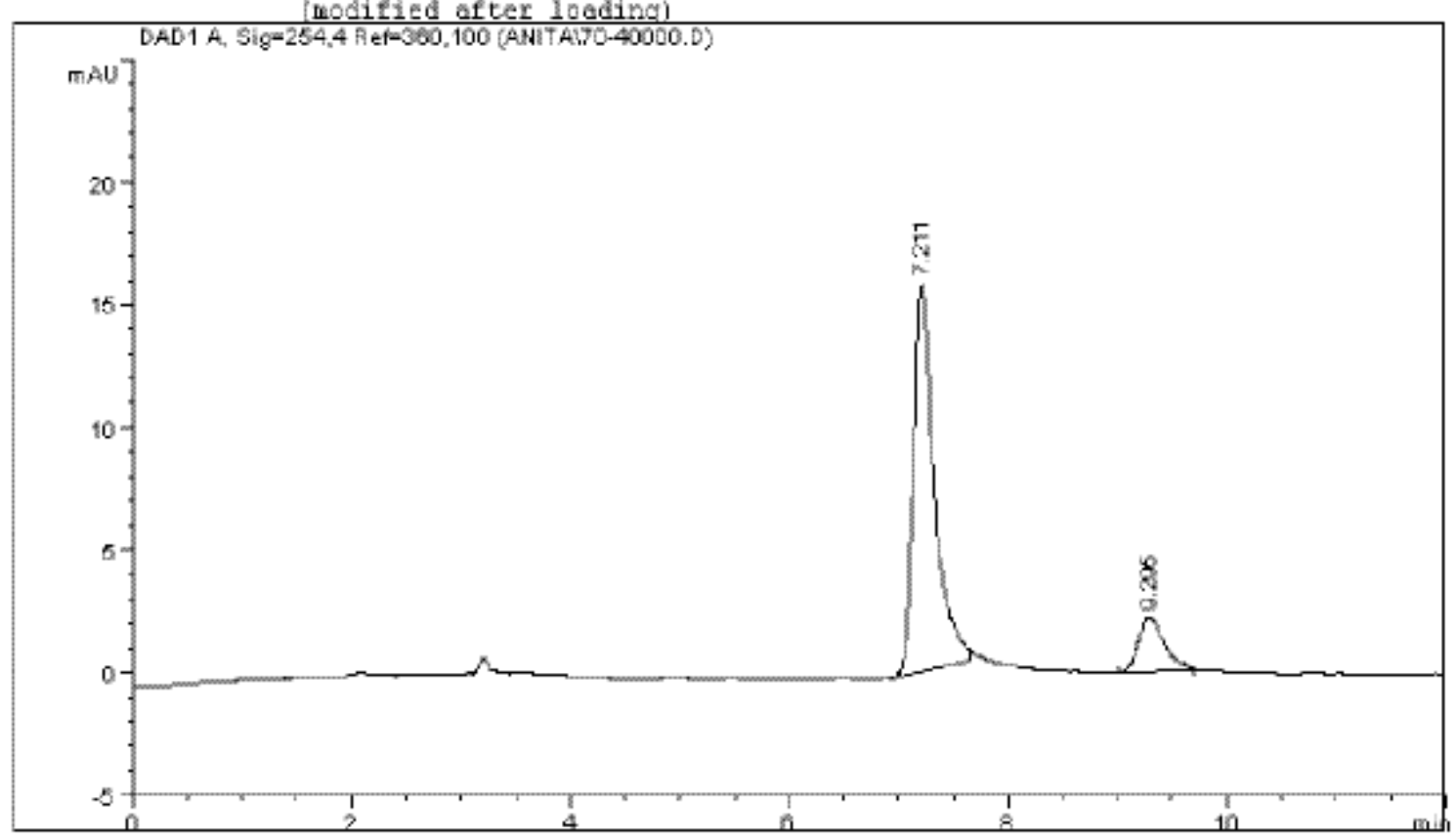

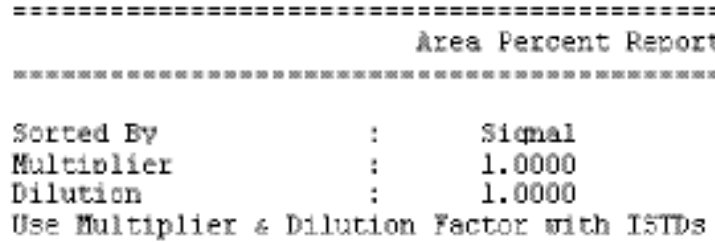

Signal 1: DADl h, \$igw254,4 Ref $\approx 360,100$

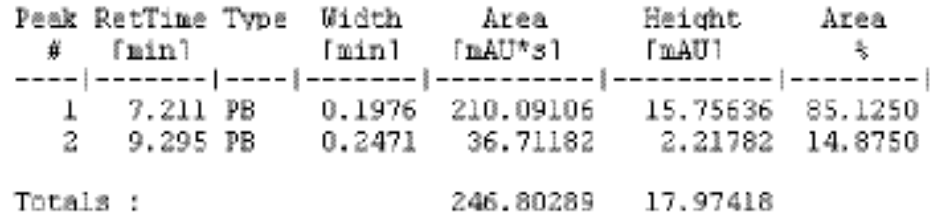

Resulcs obtained vith enhanced integrator!

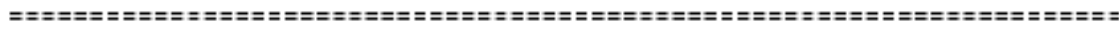

tot Fnd of Report $\pi t$ 


\section{HPLC trace of crystals from 16 used in X-ray crystallography:}

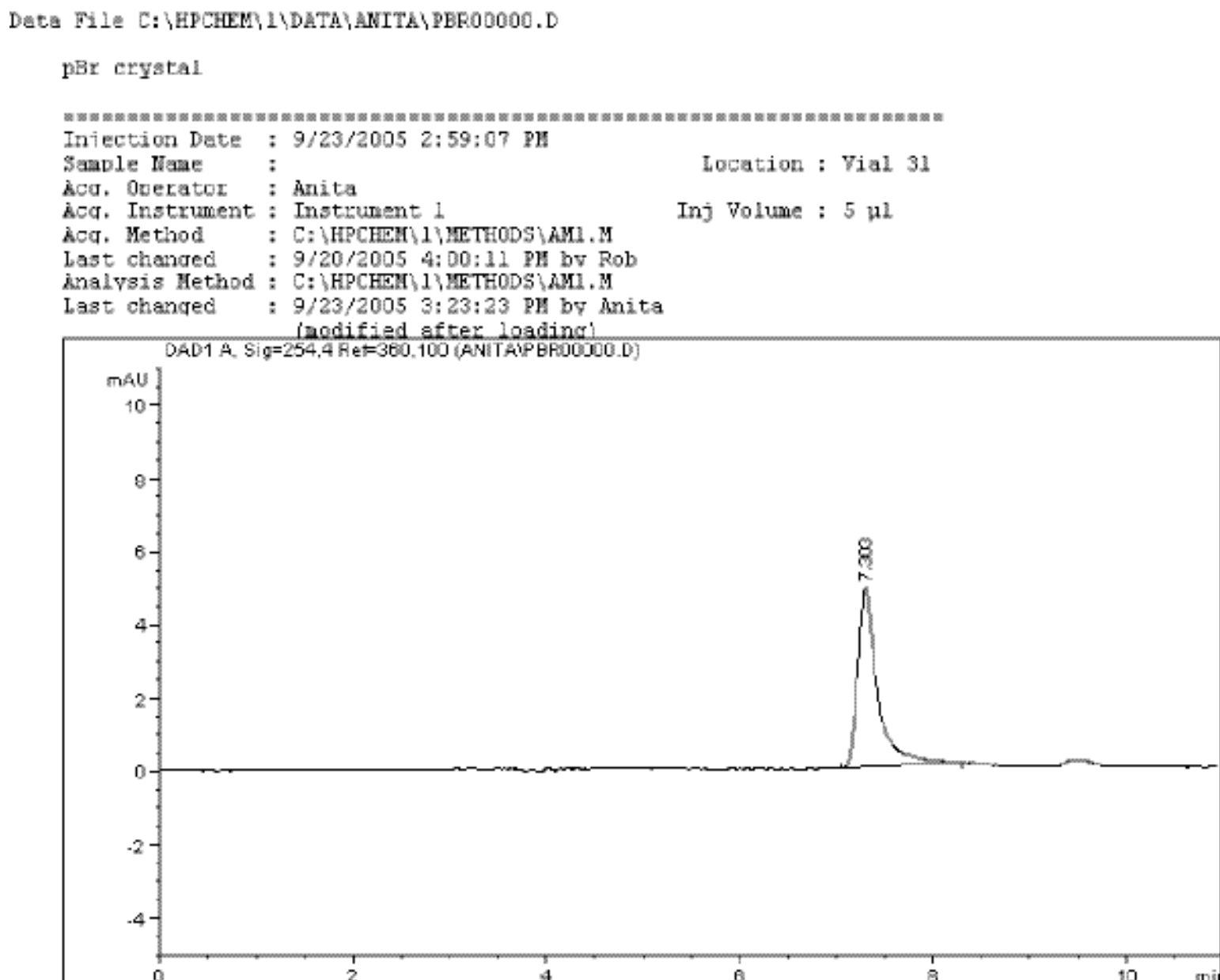

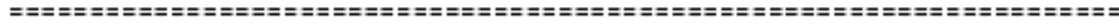
hrea Percent Revort

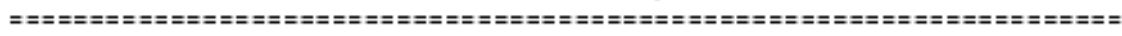

Sorted By : \$iqnal

Nultiplier : : 1.0000

Dilution : 1.0000

Use Multiplier \& Dilution Factor with ISTDs

\$ignal 1: DADL A, $\$ 1 g m 254,4$ Ref $\omega 360,100$

\begin{tabular}{|c|c|c|c|c|c|c|}
\hline Peak & $\begin{array}{l}\text { RetTine } \\
\text { [nin] }\end{array}$ & Troe & $\begin{array}{l}\text { Dideh } \\
\text { [nin\} }\end{array}$ & $\begin{array}{c}\text { Area } \\
\text { [mAU*s }\end{array}$ & $\begin{array}{l}\text { Heidut } \\
\text { 「taUt }\end{array}$ & $\underset{\text { Krea }}{\text { Xi }}$ \\
\hline n & $\mid-\infty m-\infty-\infty$ & & W & $n-m-w-w n-\infty$ & 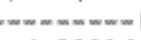 & 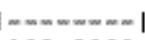 \\
\hline 1 & 7.303 & $\mathrm{~PB}$ & 0.2108 & 70.76501 & 4.89014 & 100.0000 \\
\hline Tota. & is: & & & 70.76501 & 4.89014 & \\
\hline
\end{tabular}

Results obtained with enhanced intearator! 

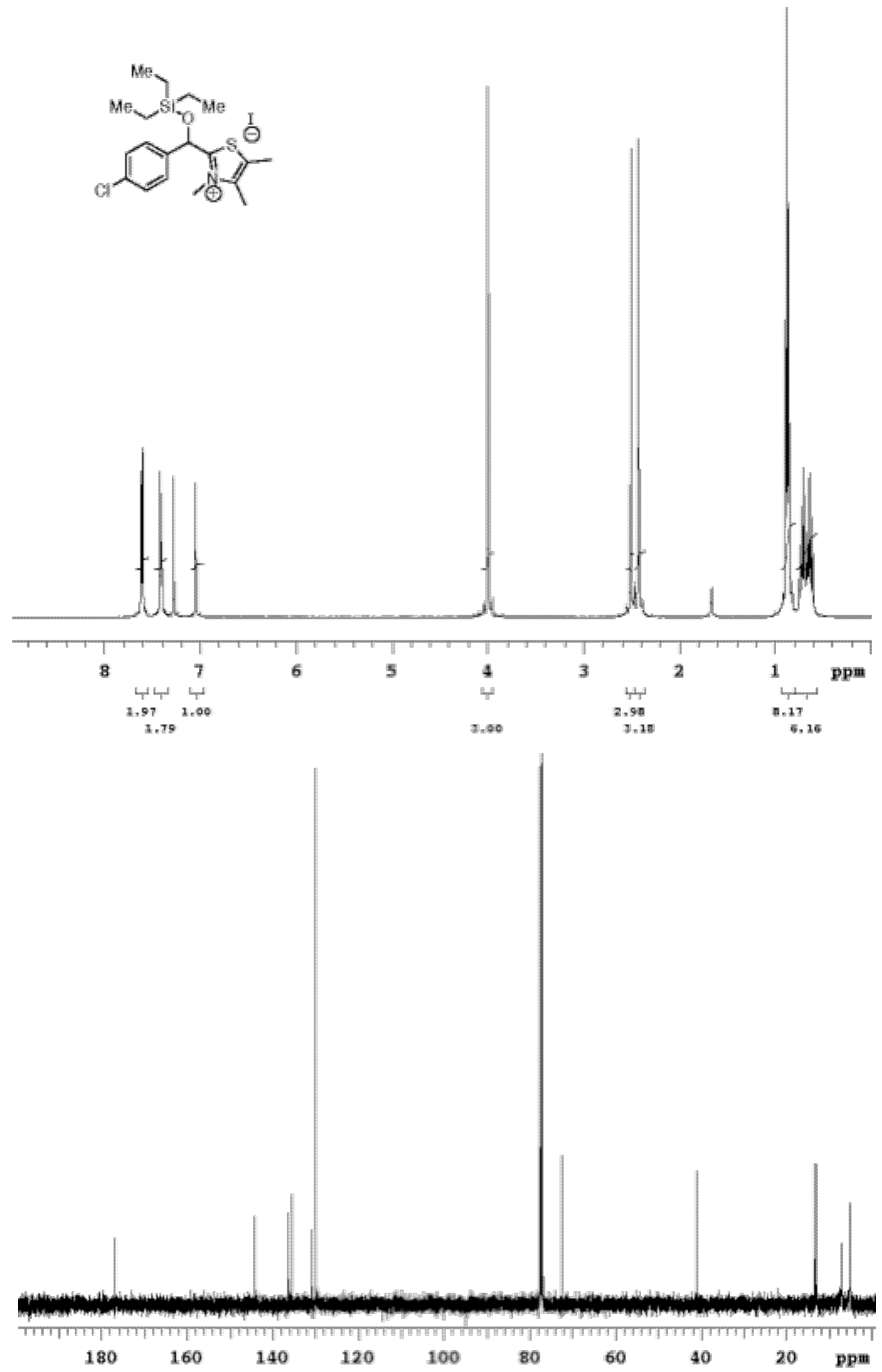

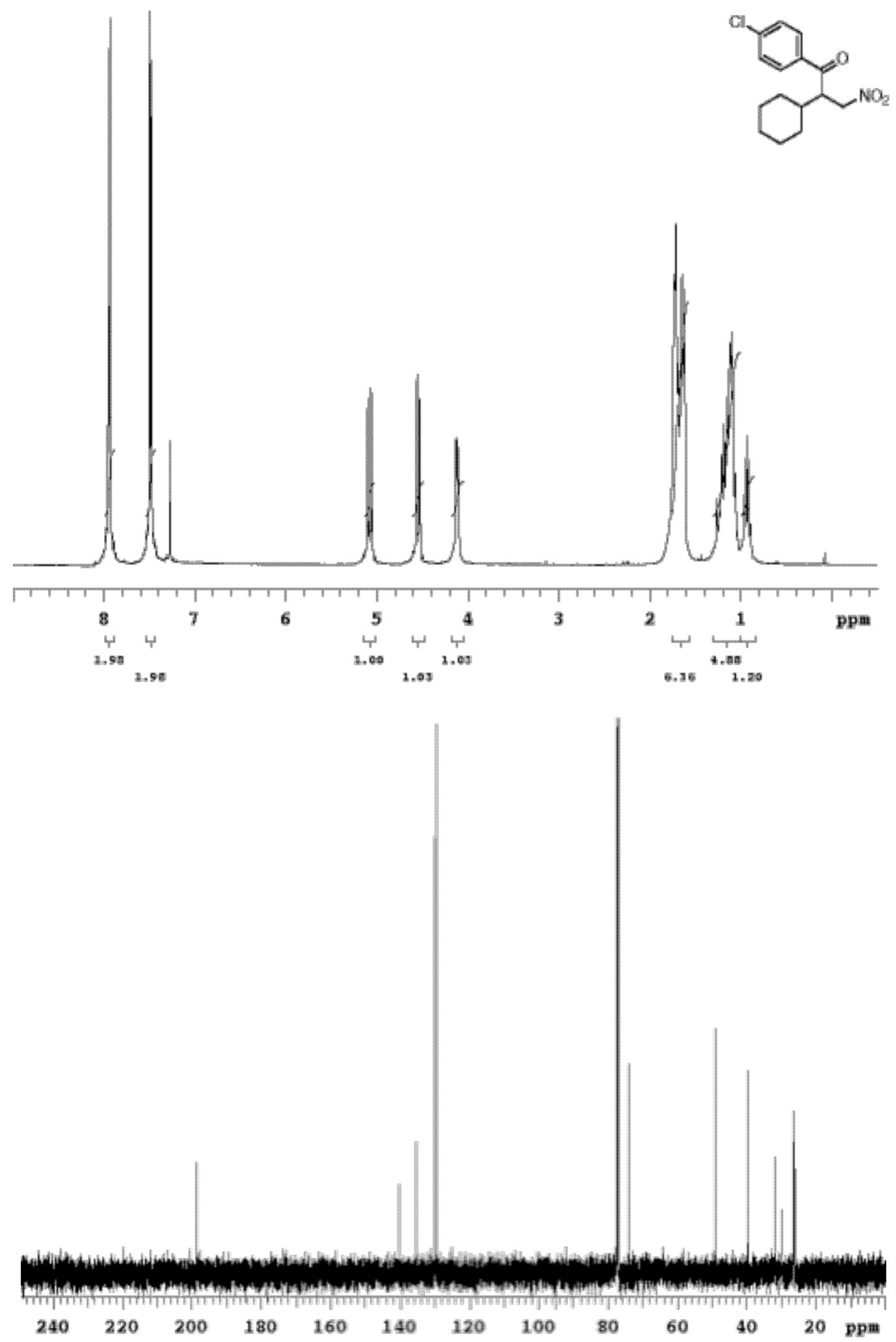


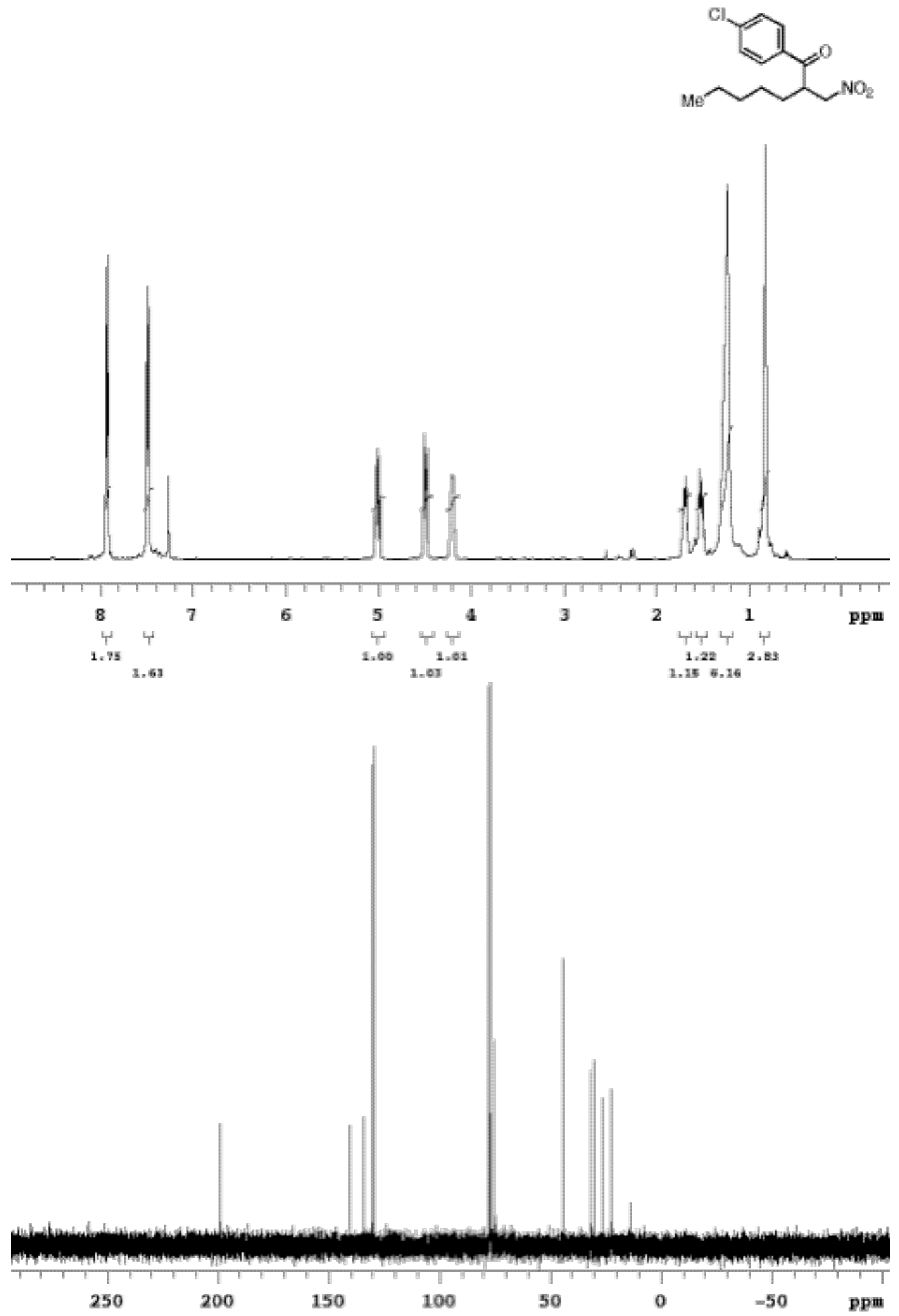



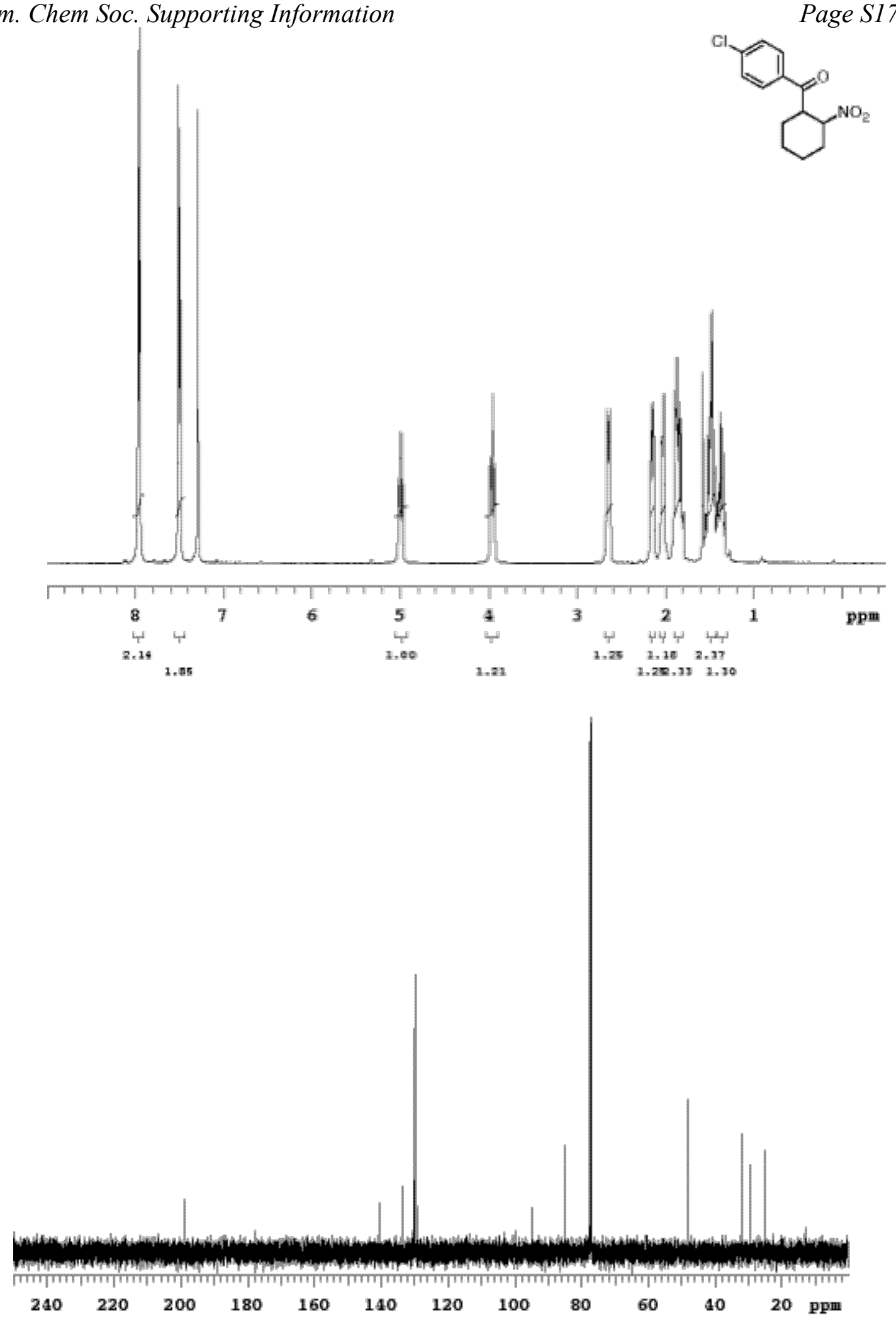

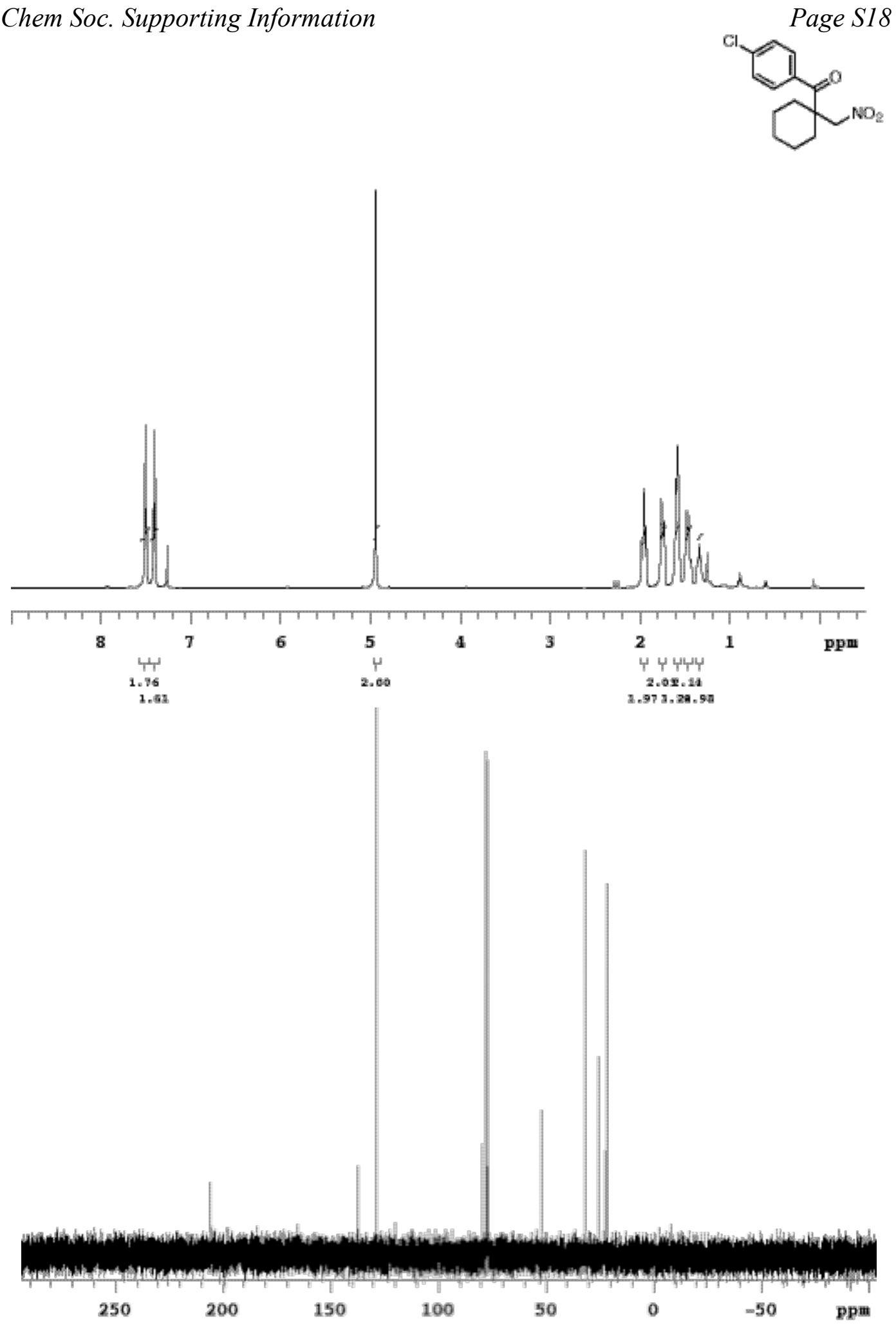

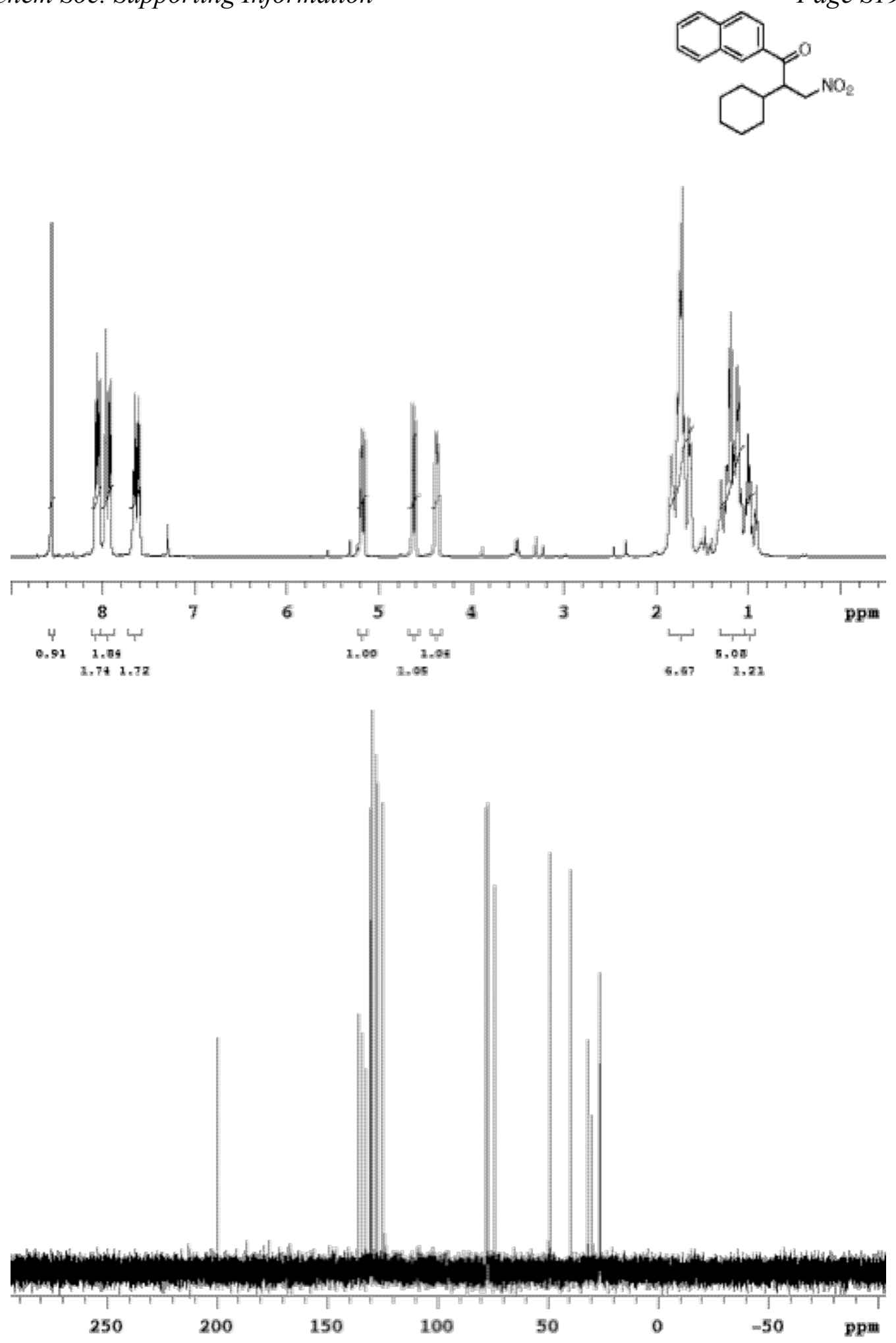